Центр медиакоммуникаций и визуальных исследований ; ХНУ имени В. Н. Каразина ; под ред. Л. В. Стародубцевой, Д.В. Петренко. - Х., 2016. - С. 9-16

3. Серебряник, Е.Э. Формирование информационно-личностной безопасности учащихся основной школы: автореф. дис. ... канд. пед. наук : спец. 13.00.01 "Общая педагогика, история педагогики и образования" / Евгений Эммануилович Серебряник. - Калининград: Балт. федер. ун-т. им. И.Канта, 2011. - 22 с.

4. Прихожан, А.М. Влияние электронной информационной среды на развитие личности детей младшего школьного возраста [Электронный ресурс] http://psystudy.ru/index.php/num/2010n1-9/283prikhozhan9.html / A.M. Прихожан // Психологические исследования: электронный научный журнал, 2010, № 1(9).

5. Губанов Д. А. Социальные сети : модели информационного влияния, управления и противоборства / Д. А. Губанов, Д. А. Новиков, А. Г. Чхартишвили. - М. : Физматлит, 2010. - 228 с. 6. Иванов Д. В. К теории потоковых структур / Д. В. Иванов // Социс. - 2012. - № 4. - С. 8 - 16

\title{
Масько К.А., Мамин А.С. \\ Пути совершенствования системы аттестации государственных гражданских служащих и оценка эффекта от их реализации
}

Белгородский государственный национальный исследовательский университет (Россия, Белгород)

doi: $10.18411 / \mathrm{j}-05-2021-239$

\section{Аннотация}

Данная статья направлена на рассмотрение отдельного процесса, происходящего в институте государственной службы- аттестацию государственных гражданских служащих, а именно пути совершения данной процедуры. Авторы предлагают ряд рекомендаций, которые позволят совершенствовать данную процедуру.

Ключевые слова: аттестация, государственный гражданский служащий, критерии оценивания, шкала оценивания.

\section{Abstract}

This article is aimed at considering a separate process that takes place in the Institute of public service - certification of public civil servants, namely, the way to perform this procedure. The authors offer a number of recommendations that will improve this procedure.

Keywords: certification, state civil servant, evaluation criteria, evaluation scale.

В настоящее время институт государственной службы постоянно развивается, совершенствуется, поскольку от качественной стороны подготовки и компетентности государственных служащих зависит профессиональное функционирование государственного аппарата в целом. Совершенствование системы аттестации служащих, состоящих на государственной гражданской службы необходимо осуществлять не только в рамках нормативно-правовой базы, но и с помощью совершенствования методов, с помощью которых происходит оценивание профессиональной деятельности служащих.

Одним из приоритетных направлений деятельности в сфере совершенствования системы аттестации государственных гражданских служащих является улучшение организационной, законодательной базы, касающейся вопросов данной системы.

Исходя из проведенного анализа данного направления деятельности, авторы приходят к следующим выводам:

- Необходимо законодательно закрепить важность процедуры аттестации, позволяющей оценить, как компетентность и знания служащих, а также создать мотивацию, благодаря которой государственные служащие будут постоянно улучшать свои знания, профессиональные знания.

- Целесообразно осуществить законодательное закрепление требования о проведении информационно- разъяснительных работах обязательных 
для всех государственных служащих. Необходимость такого положения обуславливается тем, что аттестационная комиссия и непосредственно аттестуемый имели представление об аттестации. Применение разъяснительных работ, как следствие, поможет аттестуемым минимизировать стресс в период аттестации, что позволит получать наиболее высокие результаты.

- Представляется необходимым осуществить разработку и закрепление системы детализированных критериев, в соответствии с которыми осуществляется оценка аттестуемого государственного гражданского служащего. Оценивая результаты служащего в соответствии с такими критериями, позволит избежать межличностные конфликты, субъективное отношение к аттестуемому лицу, так как критерии оценивания является важнейшей характеристикой при вынесении какого- либо решения, касающиеся аттестуемого. Многие зарубежные страны, например, Германия, Франция законодательно закрепили перечень критериев, с помощью которых осуществляется оценка профессиональных знаний, умений государственных служащих.

Авторы предлагают внедрение в Приказ Федеральной службы судебных приставов от 26.03.2021 № 99 «Об утверждении Порядка работы аттестационных комиссий Федеральной службы судебных приставов и ее территориальных органов по проведению аттестации и квалификационных экзаменов федеральных государственных гражданских служащих» некоторых критерий оценивания, которые предлагается разделить на несколько групп.

Так, например, целесообразно внедрение:

Таблица 1.

Критерии оценивания государственных гражданских служащих

\begin{tabular}{|c|c|c|c|}
\hline $\begin{array}{l}\text { Название/ } \\
\text { Критерий }\end{array}$ & Основная & $\begin{array}{l}\text { Индивидуально- } \\
\text { психологическая } \\
\text { или личностная }\end{array}$ & $\begin{array}{l}\text { Оценка } \\
\text { служебной } \\
\text { деятельности }\end{array}$ \\
\hline 1 & $\begin{array}{l}\text { Общая образованность и кругозор } \\
\text { государственного служащего }\end{array}$ & $\begin{array}{l}\text { Межличностное } \\
\text { взаимодействие }\end{array}$ & $\begin{array}{l}\text { Вклад в служебную } \\
\text { деятельность }\end{array}$ \\
\hline 2 & $\begin{array}{lr}\begin{array}{l}\text { Профессиональная } \\
\text { компетентность в }\end{array} \\
\begin{array}{l}\text { нормативно-правового } \\
\text { регулирования }\end{array} \\
\begin{array}{l}\text { деятельности } \\
\text { длужебной }\end{array} \\
\end{array}$ & $\begin{array}{l}\text { Руководящие } \\
\text { навыки и } \\
\text { лидерский } \\
\text { потенциал }\end{array}$ & $\begin{array}{l}\text { Служебная } \\
\text { дисциплина }\end{array}$ \\
\hline 3 & $\begin{array}{l}\text { Специализированные знания и } \\
\text { навыки для выполнения } \\
\text { конкретных должностных } \\
\text { обязанностей }\end{array}$ & $\begin{array}{l}\text { Иные личностные } \\
\text { качества } \\
\text { (трудолюбие, } \\
\text { порядочность...) }\end{array}$ & $\begin{array}{l}\text { Принятие решений в } \\
\text { сложных служебных } \\
\text { ситуациях }\end{array}$ \\
\hline
\end{tabular}

Анализируя прогноз успешного внедрения вышеперечисленных критерий, необходимо отметить, что они создадут возможность оценки как профессиональных, так и личностных качеств, также данные критерии позволят оценить взаимоотношения государственных служащим между друг другом, а также населением.

- В дополнении предложенных критериев оценивания, также необходимым является разработка и внедрение балльной шкалы оценивания аттестуемых государственных гражданских служащих. Данное нововведение позволит 
аттестационной комиссии выставлять конкретную объективно точную оценку в соответствии с каждым критерием, предложенными выше. Также следует предусмотреть, чтобы оформление оценки производилось на специальном листе, а оценка критерий должна производиться по пятибалльной шкале.

Примерная шкала оценивания представлена в таблице 2:

Таблица 2

Шкала оценивания

\begin{tabular}{|c|c|}
\hline 3начение & Уровень \\
\hline 1 & Неудовлетворительный \\
\hline 2 & Минимально удовлетворительный \\
\hline 3 & Удовлетворительный \\
\hline 4 & Достаточный \\
\hline 5 & Высокий \\
\hline
\end{tabular}

Следует отметить, что по мнению авторов, подобная шкала позволит аттестационной комиссии избегать субъективности при оценке аттестуемого лица, а равным счетом, поможет объективно оценивать профессиональные и личные качества каждого аттестуемого лица. При соблюдении оценки критерий по данной шкале, результаты аттестационной комиссии будут реже подвергаться обжалованию.

- Целесообразно, для повышения эффективной аттестационной процедуры обеспечить закрепление в Приказе Федеральной службы судебных приставов от 26.03.2021 № 99 «Об утверждении Порядка работы аттестационных комиссий Федеральной службы судебных приставов и ее территориальных органов по проведению аттестации и квалификационных экзаменов федеральных государственных гражданских служащих» определенных требований к независимым экспертам и специалистам, входящих в состав аттестационной комиссии. К таким требованиям можно отнести знание законодательной базы в области регулирования государственной службы; наличие служебных отношений с членами аттестационной комиссии, аттестуемыми лицами без родственных связей.

- Необходимым считается и рассмотрение вопроса об использовании дополнительных способов аттестации за исключением собеседования. Наиболее подходящим способом является проведение тестирования, содержащего в себе вопросы на знание положений Конституции РФ, законодательства в области государственной службы, а также положений трудового законодательства РФ, иных вопросов, касающихся профессиональных знаний, необходимых для исполнения служащим своих должностных обязанностей.

Таким образом, предложенные авторами рекомендации по развитию и совершенствованию системы аттестации государственных гражданских служащих имеет положительный прогноз. В первую очередь, это обуславливается прозрачностью данной процедуры, которая станет понятной для аттестуемых лиц, аттестационной комиссии. Немаловажным критерием является усовершенствование нормативной базы, детализирование критерий процедуры аттестации, конкретизация результатов аттестации.

1. Конституция Российской Федерации (принята всенародным голосованием 12.12.1993 с изменениями, одобренными в ходе общероссийского голосования 01.07.2020) // Официальный 
интернет-портал правовой информации. - URL: http:/www.pravo.gov.ru. (дата обращения:15.04.2021).

2. О государственной гражданской службе Российской Федерации: Федеральный закон Российской Федерации от 27.07.2004 №79-Ф3 (ред. от 24.03.2021) // Собрание законодательства РФ. 02.08.2004. - № 31. - ст. 3215.

3. Об утверждении Порядка работы аттестационных комиссий Федеральной службы судебных приставов и ее территориальных органов по проведению аттестации и квалификационных экзаменов федеральных государственных гражданских служащих: Приказ ФССП России от 26.03.2021 № 99 // Официальный интернет-портал правовой информации. - URL: http://pravo.gov.ru (дата обращения: 30.04.2021)

4. Ковтков, Д. И. Правовое регулирование профессионального развития государственных гражданских служащих Российской Федерации: моногр. / Ковтков Дмитрий Иванович. - М.: Юстицинформ, 2017. - 396 с.

5. Старилов, Ю. Н. Государственная служба и служебное право / Ю. Н. Старилов. - М.: Норма, 2015. $-422 \mathrm{c}$.

\section{Матвеева И.В., Саможенов С.Н. \\ Возможности подготовиться к письменной части ЕГЭ по немецкому языку на материалах международных экзаменов уровня В1+/B2}

ФГБОУ ВО «Нижегородский государственный лингвистический университет имени Н. А. Добролюбова

(Россия, Нижний Новгород)

doi: $10.18411 / l j-05-2021-240$

\section{Аннотация}

Данная статья посвящена общей характеристике письменной части ЕГЭ по немецкому языку и международных экзаменов Goethe-Zertifikat, ÖSD, сравнению форматов, обучение стратегиям, необходимым для успешной сдачи ЕГЭ по немецкому языку.

Ключевые слова: ЕГЭ, немецкий язык, тестирование, метод самоконтроля, международный экзамен

\section{Abstract}

This article is devoted to the general description of the written part of the exam in German-EGE (national exam) and the international exams Goethe-Zertifikat, ÖSD, format comparison, training in the strategies necessary for successful passing of the exam in German.

Keywords: national exam, German, testing, self-control method, international exam

Существует много способов для успешного прохождения экзаменационного теста. Среди обязательных: посещение уроков в школе, дополнительных занятий, самостоятельное повторение тем. Школьник подписывается на рассылку образовательного материала в социальных сетях, регистрируется на порталах, скачивает литературу, так как необходимым условием для успешной сдачи экзамена является уровень владения языком В1/B2 по Европейской шкале оценивания уровня владения языками.

С форматом ЕГЭ необходимо познакомиться: для успешного выполнения разделов ЕГЭ по немецкому языку полезно приучать себя к внимательному чтению и неукоснительному выполнению инструкций, использующихся в материалах ЕГЭ. [1] Выполняя тестовые задания, школьник проверяет качества приобретенных знаний, а также формируются соответствующие психотехнические навыки саморегуляции и самоконтроля («сбрасывать» напряжение и восстанавливать работоспособность, правильно распределять время).

Применительно к иноязычной коммуникативной компетенции ЕГЭ является итоговой формой контроля, однако одной тренировки формата недостаточно. Чтобы 